\title{
LA NOCIÓN DE “AFEPTO” COMO SABOTAJE DE LA RELACIÓN ENTRE FILOSOFÍA Y LITERATURA
}

\section{THE NOTION OF “AFEPT” AS A SABOTAGE OF THE RELATIONSHIP BETWEEN PHILOSOPHY AND LITERATURE.}

\section{Manuel ASENSI PÉREZ \\ Universitat de València}

Resumen: La creación del neologismo "afepto" viene a poner en entredicho la diferencia que la tradición metafísica ha establecido entre la filosofía y la literatura. Aunque son dos campos que no se pueden condensar en un solo nombre debido a la gran variedad que presentan, siempre la filosofía ha tratado de marcar las distancias respecto a la literatura. En este trabajo, mediante una lectura atenta de Mukarovsky y su teoría de la función estética, y teniendo en cuenta la tradición a la que ha dado lugar, se explica la razón por la que el "afepto", una de los conceptos clave de la crítica como sabotaje o teoría de los modelos de mundo, desvela el poder epistemológico de la literatura y el hecho de que pueda ser un fuente de la verdad aunque sea negativa. El ejemplo que se pone para guiar el análisis es el del poema de Juan Ramón Jiménez "El viaje definitivo".

Palabras clave: crítica y sabotaje, teoría de los modelos de mundo, filosofía y literatura, Juan Ramón Jiménez

Abstract: The creation of the neologims "afept" comes to question the difference between philosophy and literature in the sense of the metaphysical tradition. Although it is no posible to sum up that two fields in only one name, because both have a lot of variety, philosophy has always tried to mark the distances in relation to literature. Our subject explains, through a close reading of Mukarovsky's theory of the aesthetic function, and taking into account the tradition that it inaugurated, the reason why the "afept", one of the main concepts of the criticism as sabotaje or the theory of world's model, reveals the epistemologic power of literatura, and that it can be the source of the truth, even if it is negative. We use the Juan Ramón Jiménez's poem "El viaje definitivo" as a guide for our argument.

Key words: Criticism as sabotaje, Theory of the world's model, philosophy and literature, Juan Ramón Jiménez. 
$\mathrm{C}$ uando en los años sesenta, Tzvetan Todorov afirmó, junto a una larga lista de autores, empezando por Jakobson y Mukarovsky (ed. 2000), que la literatura era un discurso no referencial creó una corriente de pensamiento sobre el hecho literario que sin duda podría ser calificada de "estética", y que ha tenido una influencia desmesurada. Así, por ejemplo, en su texto “¿Qué es el estructuralismo? Poética”, Todorov se hacía eco de los lógicos y escribía:

La referencia (no hay que confundir esta evocación mediante el signo con el objeto mismo, extralingüístico, o referente) es la capacidad que tiene el signo de evocar algo distinto de sí mismo. El sentido o, como diremos de ahora en adelante, la literalidad, es la capacidad que tiene el signo de ser aprehendido en sí mismo y no en la medida en que remite a otra cosa (Todorov, 1971, p. 112).

Terry Eagleton resumía bien esta forma de pensar la literatura:

Podríamos decir que la literatura es un discurso 'no pragmático'. Al contrario de los manuales de biología o los recados que se dejan para el lechero, la literatura carece de un fin práctico inmediato, y debe referirse a una situación de carácter general (Eagleton, 1998, p. 9).

Esa carencia de fin práctico fue confirmada definitivamente por la teoría pragmática de la literatura, para la que la literatura bajo cualquiera de sus formas carece de un valor pragmático, entiéndase "performativo", real. Así lo planteó Austin en la segunda de sus conferencias cuando examinaba las condiciones bajo las que un realizativo podía ser exitoso:

Una expresión realizativa será hueca o vacía de un modo peculiar si es formulada por un actor en un escenario, incluida en un poema, o dicha en un soliloquio (...) En tales circunstancias el lenguaje no es usado en serio, sino en modos o maneras que son dependientes de su uso normal (Austin, 1982, p. 63).

Como se sabe, estas palabras de Austin están en la base de la deconstrucción derridiana entre el performativo serio y el ficticio (Derrida, 1972), que además fue el inicio de una larga discusión con Searle (Derrida, 1988) ${ }^{2}$. Pero más allá de la deconstrucción derridiana que afecta a las condiciones de posibilidad de los actos performativos, digamos que el argumento de Austin viene a decir que no es lo mismo un juramento en el plano de la realidad que en una obra de teatro. A fin de cuentas, dos personas que contraen matrimonio en una obra de teatro no quedan casados al finalizar la obra (menos mal, podríamos decir). Sin embargo, esta noción de performatividad toma como punto de referencia la relación texto-realidad, y en cuanto a dicha relación se le podría conceder la razón. No sería el caso de la filosofía, ya que de Platón a Derrida ésta habla del mundo de una manera u otra, por mucho que a veces su referente pueda ser más o menos manifiesto.

\footnotetext{
${ }^{1}$ No en vano Mukarovski definía la función estética como aquella en la que el signo llama la atención sobre sí mismo suspendiendo la referencia. De hecho, en este texto vamos a discutir con cierta profundidad las tesis del autor praguense.

${ }^{2}$ En este libro de Derrida, traducción al inglés de varios trabajos de Derrida y respuestas de John Searle, se condensa lo más esencial de esa discusión.
} 
¿Pero qué sucede, como defiende, la crítica como sabotaje, si tomamos en cuenta la relación entre el texto y el receptor? Ahí las cosas cambian, porque si un discurso artístico es capaz de modificar la conciencia de dicho receptor, entonces la performatividad ya no es ficticia, sino real y potencialmente efectiva. Esto último no es una hipótesis de trabajo, sino la reiteración de un hecho bien descrito por los estudios descoloniales (Fanon, 2019, por ejemplo) y los estudios de género (Teresa de Lauretis, 1987, como otro ejemplo).

Lo que hace la teoría de los modelos de mundo es cambiar la dirección del performativo. Cierto es que Don Quijote carece de un referente histórico externo, pero también lo es que el propio personaje plantea el problema psicótico de la imitación de los personajes de los libros de caballería. Este hecho, indudable se mire por donde se mire, plantea el problema de un tipo de efecto performativo distinto: el que se da cuando un lector se siente incitado a actuar de un modo u otro según lo que ha leído o visto. Por decirlo con Fanon, ¿cómo sería posible que un negro se percibiera a sí mismo como blanco si no fuera porque tiene delante algo que le incita a ello, un film de Tarzán? Sin entrar en pormenores de los conceptos fundamentales de la crítica como sabotaje (Asensi, 2013), digamos que esto afecta a nuestra concepción de la literatura y a su relación con la filosofía. ¿Por qué y de qué manera? Para responder a esta pregunta hace falta incursionarse brevemente en la noción de "silogismo" y en la correlativa de "modelo de mundo".

¿Qué es lo que hace posible pasar del contenido de un discurso a la realidad de las circunstancias de un lector o espectador? La estructura silogística de dichos discursos. Si un silogismo presenta una estructura que pasa de lo general a lo particular (todo hombre es mortal; Sócrates es un hombre; por tanto Sócrates es mortal) o de lo particular a lo general, es claro que para que Don Quijote se convenza de que es un caballero andante, ha leído unas premisas que le permiten llegar a su caso particular. Partimos de la hipótesis de que todo discurso con capacidad performativa posee una estructura silogística.

Ahora bien, si el lector no encontrara alguna clase de analogía entre sus circunstancias y el texto no habría forma de establecer una conexión entre un ámbito y otro. Todo silogismo encuentra su base en el hecho de que todo discurso crea un modelo de mundo que le permite al lector o espectador establecer una conexión. Un modelo de mundo no es un mundo posible en la medida en que no apunta en una dirección exterior al mundo, sino un modelo que apunta al mundo mismo. Incluso en el caso de que un lector o lectora pretendan evadirse de la realidad, va de suyo que ese mundo a través del que se escapa a otro mundo, contiene elementos de la realidad ya que así es le cómo gustaría que fuera ese mundo.

En el caso concreto de la literatura, de lo que institucionalmente llamamos "literatura", ello implica que en tanto silogismo la literatura contiene una dimensión conceptual. Se trata de un silogismo que llamamos "afectivo", para el que se creó el neologismo "afepto", el cual da a entender que en lo que toca al arte el signo comporta una doble dimensión afectiva y conceptual. Como se recordará, Félix Guattari y Gilles Deleuze (1993) establecieron una diferencia entre el arte y la filosofía a partir de la oposición entre el afecto-percepto y el concepto. 
No son éstas nociones que se puedan definir sencillamente dada su complejidad, pero de lo que no cabe duda es de que estos autores se mantienen fieles a la tradición argumentando que el arte crea afectos y perceptos, y la fillosofía conceptos. He aquí cómo lo dicen: "Sólo disponemos por el momento de una hipótesis muy amplia: de frases o de un equivalente, la filosofía saca conceptos (que no se confunden con ideas generales o abstractas), mientras que la ciencia saca prospectos (proposiciones que no se confunden con juicios), y el arte saca perceptos y afectos (que tampoco se confunden con percepciones o sentimientos)." (Deleuze y Guattari, 1993, p. 30). Y más adelante aseguran: "La diferencia entre los personajes conceptuales y las figuras estéticas consiste en primer lugar en lo siguiente: unos son potencias de conceptos, y los otros potencias de afectos y perceptos" (Deleuze y Guattari, 1993, p. 67).

Valdría la pena tener presente que al hablar de filosofía y literatura estamos hablando de dos campos muy complejos afectados por una fuerte historicidad. Es difícil englobar en un mismo saco la filosofía analítica y la crítica herideggeriana de la metafísica. Así que antes habría que aclarar a qué filosofía y a qué literatura nos referimos.

Pero vamos a suponer que tomamos como punto de referencia las tesis de Deleuze y Guattari, y partimos de ese reparto creativo: el arte, afectos-perceptos, y la filosofía, conceptos. Atribuirle a la filosofía la creación de conceptos no es algo difícil, aunque hay casos en los que ello no está tan claro, tal y como ocurre con Nietzsche, Heidegger o Derrida. En la filosofía el silogismo lógico resulta claro, Sócrates es un buen ejemplo de ello. Pero atribuirle al arte la creación de afectos-perceptos, ahí está el problema para la teoría de los modelos de mundo. Claro, no solo para esta teoría, porque Paul de Man (1979) se resistió también, avant la lettre, a esa división. Según de Man, el poeta es

[...] la fuente de la verdad; si la verdad es el reconocimiento del carácter sistemático de cierto tipo de error, entonces será totalmente dependiente de la existencia previa de este error. Filósofos de la ciencia como Bachelard o Wittgenstein dependen notoriamente de las aberraciones de los poetas (de Man, 1990, p. 31).

Pero quizá quien se resiste con más fuerza a ese reparto entre la filosofía y la literatura es la crítica como sabotaje. Y la razón de esa resistencia la vamos a ver de inmediato mediante un ejemplo muy alejado del campo conceptual: un poema de Juan Ramón Jiménez titulado "El viaje definitivo".

Y yo me iré. Y se quedarán los pájaros cantando.

Y se quedará mi huerto con su verde árbol, y con su pozo blanco.

Todas las tardes el cielo será azul y plácido, y tocarán, como esta tarde están tocando, las esquilas del campanario.

Se morirán aquellos que me amaron y el pueblo se hará nuevo cada año; y lejos del bullicio distinto, sordo, raro del domingo cerrado, del coche de las cinco, de las barcas del baño, en el rincón oculto de mi huerto encalado, entre la flor, mi espíritu errará callado. 


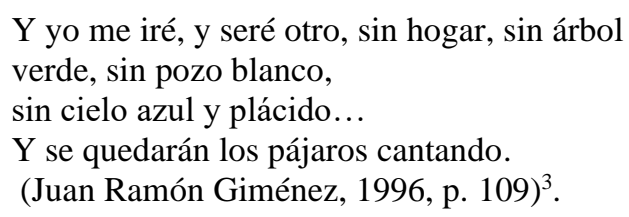

Hay algo que no se puede poner en duda: el carácter afectivo de este poema. Ese inicio de verso que dice "Y yo me iré" ya nos evoca la muerte de una forma poderosa, especialmente cuando el narrador poemático enumera las cosas que quedarán en el mundo tras su desaparición. Ese "afecto" se dobla debido a que está enunciado en primera persona en tanto "experiencia" del yo singular, pero que por ello mismo, en virtud de esa individualidad, es capaz de asimilar al "yo" de todos los lectores. Tanto considera el narrador poético que deja atrás las cosas de su mundo que su "espíritu" vuelve para errar en silencio por entre esas cosas: "mi espíritu errará callado". Este poema es un buen ejemplo de cómo un silogismo pasa de su estructura particular a una generalidad en la que queda englobado todos los "yoes" lectores. Los adjetivos empleados (el "verde" árbol, el pozo "blanco", el "azul" del cielo, el rincón "oculto", el huerto "encalado") van modelizando el percepto de este poema, apelando a los sentidos y a los sentimientos. Y es por eso que Deleuze y Guattari hablan justamente de los afectos y de los perceptos como específicos del arte.

Ahora bien, ¿es seguro que esa característica atribuida por esos dos pensadores a la literatura y el arte viene sola? Tal y como ha sido señalado por la crítica juanramoniana, no era un motivo en 1910 nuevo en la obra del poeta. Ya en 1900 había escrito el poema "Yo no volveré" que guarda un gran parecido con este otro:
Yo no volveré. Y la noche tibia, serena y callada, dormirá el mundo, a los rayos de su luna solitaria.
Mi cuerpo no estará allí, y por la abierta ventana entrará una brisa fresca preguntando por mi alma... (Juan Ramón Jiménez, 1996, pp. 88-89).

Esta reiteración de un mismo motivo es lo que nos llevó en la teoría de los modelos de mundo a hablar del "mundo" en tanto elemento de la geografía psíquica del autor. Este camino no lo vamos a seguir en este texto. Baste con esta mención.

En este poema ya argumentaba el poeta que después de que él se fuera, el mundo, con sus noches y sus días, con su luna, con su brisa fresca, quedaría ahí sin él. Los elementos que aparecían en este poema de 1900 no son los mismos que aparecen en el poema objeto de nuestro análisis, pero hay un denominador común: el mundo queda tras la muerte del poeta. ¿Es esto solo un afecto-percepto o es, a la vez, un concepto del mundo el que lleva aparejado? Porque veamos, el narrador poemático, al decir "Y yo me iré. Y se quedarán los pájaros cantando" está ofreciendo un concepto de mundo, un

\footnotetext{
${ }^{3}$ La versión de este poema pertenece a la edición de Gómez Redondo (ed.) (1996).
} 
concepto de espacio y de tiempo que son independientes del sujeto que los experimenta. Y esto, queramos o no, lo veamos o no, es una respuesta voluntaria o involuntaria a Kant.

Abramos la Crítica de la razón pura y vayamos al apartado en el que el filósofo alemán trata la estética trascendental, en concreto al epígrafe 8 titulado "Observaciones generales sobre la estética trascendental". Es un título bastante ilustrativo de lo que viene a continuación tras las exposiciones trascendentales del espacio y del tiempo, la dos condiciones fundamentales del mundo. En efecto, ahí leemos lo siguiente, algo que al buen conocedor de Kant no sorprenderá en absoluto:

\footnotetext{
Si suprimiéramos nuestro sujeto o simplemente el carácter subjetivo de los sentidos en general, todo el carácter de los objetos, todas sus relaciones espaciales y temporales, incluso el espacio y el tiempo mismos, desaparecerían. Como fenómenos, no pueden existir en sí mismos, sino sólo en nosotros. Permanece para nosotros absolutamente desconocido qué sean los objetos en sí, independientemente de toda esa receptividad de nuestra sensibilidad (Kant, 1978, p. 82).
}

Si Juan Ramón hubiera tenido en mente este modelo de mundo que construyó Kant y que supuso toda una revolución, probablemente no habría escrito: "Y yo me iré. Y los pájaros se quedarán cantando", sino más bien "Y yo me iré. Y los pájaros desaparecerán conmigo", que sin duda es menos poético, pero posiblemente habrían curado un poco la neurosis del poeta de Moguer. Sea como sea, lo que el texto de Juan Ramón no puede evitar es arrastrar una dimensión conceptual que tiene que ver con su modelo de mundo y que es capaz de modelizar a los lectores o lectoras que leen ese poema. De hecho, el afecto triste y melancólico que trasmite es inseparable de un concepto de mundo en el que los seres humanos mueren y dejan detrás aquellas cosas que les eran queridas. Eso es justo el "afepto", la imposibilidad de separar un afecto de un determinado concepto de mundo.

Ahora bien, según la tradición estructuralista checa la polarización de las funciones del lenguaje no es entre una función afectiva (por muy importante que esta fuera para una tradición estilística como la de Dámaso Alonso (1966)) y una función conceptual, sino entre una función autorreferencial y una función referencial. Partiendo de la teoría funcionalista del lenguaje, que se expuso en las bien conocidas tesis del 29 (Trnka et alii, 1971), y que tuvo en Bühler y en Jakobson dos de sus mejores exponentes, Mukarovsky lanzó una teoría acerca del lenguaje poético, heredera de la tradición formalista rusa. En ella afirmaba que aunque en el lenguaje poético conviven varias funciones lingüísticas (referencial, emotiva, conativa, metalingüística, etc.), la que predomina es aquella en la que el lenguaje llama la atención sobre sí mismo.

En efecto, en su estudio sobre la denominación poética había asegurado en sus inicios que "por denominación poética entendemos toda denominación que se halla en un texto con función estética predominante" (Mukarovsky, 2000, p. 96), siendo esa función estética aquella en la que el lenguaje llama la atención sobre sí mismo. El teórico checo comienza a definir la "denominación poética" apartándola de la realidad, diciendo que "está determinada, en primer término, no tanto por su relación con la realidad referida, cuanto por el modo de su inserción en el contexto" (Mukarovsky, 2000, p. 96). ¿Y a qué se refiere cuando habla de "inserción en el contexto"? A la forma como las palabras se relacionan unas con otras, en sus diferentes niveles lingüísticos. Así, por ejemplo, cuando el poema de Juan Ramón dice: 
Y yo me iré. Y se quedarán los pájaros cantando.

Y se quedará mi huerto con su verde árbol,

y con su pozo blanco.

Observamos que la forma como esas palabras se insertan en el contexto establece una relación entre /cantando/, /árbol/ y /blanco/, a partir de una rima asonante que se produce en esas palabras de final de verso. Hay un valor informativo en el hecho de decir "verde árbol" y "pozo blanco" dado que nos proporciona una información acerca de cómo son el árbol y el pozo de los que se habla en el poema. Pero su valor poético no se desprende de esa información, sino del hecho, vendría a subrayar Mukarovsky, de la forma como esas palabras se relacionan con otras de su mismo contexto dando lugar a que el lector se fije en el significante mismo. Puesto que en el momento el que escribe ese texto Mukarovsky tiene en mente la teoría de las funciones lingüísticas de Karl Bühler, se refiere a ellas diciendo que desde un punto de vista comunicativo, la función referencial, emotiva y apelativa son aceptables, pero no así desde la perspectiva de la enunciación poética. Esta nueva función, insiste Mukarovsky, se caracteriza porque en ella se "enfoca la atención sobre la construcción misma del signo lingüístico" (Mukarovsky, 2000, p. 99). Es a esa modalidad enunciativa a la que llama "función estética".

¿Y de dónde viene, pues, la idea del "afecto" artístico? Digamos de entrada que Mukarovsky no es ajeno a esa dimensión afectiva, ya que en el mismo texto se refiere al hecho de que esa autoreferencialidad del signo lingüístico provoca un "placer estético" (Mukarovsky, 2000, p. 102). La pregunta que hacíamos antes en torno a la cuestión del "afecto" encuentra aquí una primera respuesta, pues como se ve el mismo Mukarovsky extiende una línea de conexión entre el hecho de que el signo llame la atención por sí mismo y el placer que se obtiene de ello. Por consiguiente la polaridad establecida por Deleuze y Guattari cuando tratan la relación entre la filosofía y el arte encuentra aquí uno de sus apoyos.

Pronto vamos a descubrir cómo Mukarovsky no puede evitar reintroducir la referencia de la obra poética a la realidad, al igual que ya había hecho con anterioridad Sklosvsky ${ }^{4}$. Aunque la función estética tiene como característica fundamental el llamar la atención sobre el signo lingüístico mismo, ello no obsta para que no excluya la relación entre la obra y la realidad, sino que resulte "en beneficio de esta relación" (Mukarovsky, 2000, p. 102). Comentando los efectos de la lectura de la novela de Dostoievski Crimen y castigo, argumenta que "los que leen esta obra de Dostoievski reaccionan a la lectura con sus experiencias más íntimas. Cada lector tiene la impresión de que sua res agitur" (Mukarovsky, 2000, p. 102).

\footnotetext{
${ }^{4}$ Recuérdese que Sklovski, en su trabajo "El arte como procedimiento" había ligado la desautomatización y extrañamiento lingüísticos a una redescubrimiento de la realidad: "Y he aquí que para provocar la sensación de vida, para sentir los objetos, para probar que la piedra es de piedra, existe aquello que denominamos arte. El fin del arte es ofrecer una sensación del objeto como visión y no como reconocimiento; el procedimiento del arte es el procedimiento de singularización de los objetos, así como el procedimiento que consiste en oscurecer la forma, en aumentar la dificultad y la duración de la percepción" (Torodov, 1965, p. 83).
} 
¿Qué conclusión se puede extraer de esto? Pues que en el corazón mismo de la teoría de la autoreferencialidad del signo estético no puede evitarse implicar la alusión de la obra literaria y/o artística a la realidad del lector o espectador. El problema es que la teoría acerca de que en la obra artística el signo llama la atención sobre sí mismo ha ocultado la dimensión performativa de dicha obra artística, aquella mediante la que puede llegar a modelizar la subjetividad del receptor o receptora. Este es el hecho que constituye el punto de partida de la teoría de los modelos de mundo, opuesta por ello a la teoría de los mundos posibles ${ }^{5}$.

El mismo Mukarovsky se va a referir a esa modelización de la subjetividad cuando en ese estudio sobre la denominación poética diga: "Puesto que el individuo es miembro de una colectividad y su concepción de la realidad coincide a grandes rasgos con el sistema axiológico válido para dicha colectividad, la poesía ejerce influencia, por medio de los individuos escritores y lectores, sobre la manera como concibe el mundo la sociedad entera" (Mukarosky, 2000, p. 103). A pesar de que en la denominación poética la relación con la realidad está atenuada debido a su carácter autorreferencial, sin embargo es en virtud de esa misma autoreferencialidad que llega a influir en los sujetos lectores y/o espectadores. Uno de los principios de la teoría de lo modelos de mundo afirma que la distancia de todo signo (no solo del poético) respecto a la realidad designada (lo que Lacan denomina "semblante") ${ }^{6}$ constituye la base para decir que es necesario sabotear los discursos porque ineludiblemente deforman la realidad.

Esas observaciones de Mukarovsky no le hicieron proseguir la línea de investigación que se abre a propósito de la influencia sobre la manera en que la sociedad concibe el mundo, ya que la indagación estructuralista siguió por el lado exclusivamente lingüístico, tal y como demuestra por ejemplo las conclusiones de Todorov y del estructuralismo en general. Ello a pesar de la conclusión del ensayo de Mukarovsky: el debilitamiento de la función referencial en la función poética entra, sin embargo, "en relación con todo el conjunto de relaciones vitales del sujeto" (Mukarovsky, 2000, p. 104). En realidad, lo que verdaderamente ocurre es que el lenguaje poético funciona como el modelo de lo que ocurre con cualquier clase de signo, esto es, que está apartado de la realidad fenoménica.

La razón de que se haya hecho este recorrido por la teoría de la función estética de la denominación poética era para demostrar que ni en las versiones más estructuralistas de la teoría literaria se ha podido borrar del todo el tipo de efecto performativo del campo artístico en su relación con el lector o espectador. Bien es verdad que en el caso de Mukarovsky ello se hizo de forma tangencial y secundaria, pero sirve para darse cuenta de que la diferencia entre la filosofía y la literatura no está tan clara. Las nociones de "modelo de mundo" y de "silogismo" son las que explican el por qué no se pueden separar tan nítidamente. ¿Quién ofrece un modelo de mundo más fuerte, más definido, el texto de Kant o el de Juan Ramón?

\footnotetext{
${ }^{5}$ Para las diferencias entre la teoría de los modelos de mundo y la teoría de los mundos posibles véase Asensi (2016, pp. 38-55).

${ }^{6}$ Sobre el "semblante" véase el seminario 18 en Lacan (2006). "Todo lo que es discurso solo puede presentarse como semblante, y nada se construye allí sino sobre la base de lo que se llama significante. Desde la perspectiva en que lo presento hoy, el significante es idéntico al estatuto como tal del semblante" (Lacan, 2009, p. 15).
} 
Si volvemos sobre los dos textos observamos que mientras Kant sitúa su modelo de mundo explícitamente en la superficie de su texto, ofreciendo una modalidad analítica, lo que hace Juan Ramón es representar un modelo de mundo sintético en el que este se ofrece sin más de forma no analítica. No quiere decirse que ello suceda de ese modo en todo texto literario y en todo texto filosófico. Sería necesaria toda una investigación de carácter diacrónico y sincrónico en torno a la forma en que se expresan los modelos de mundo en el campo literario.

Otro aspecto que llama la atención cuando se compara el texto de Juan Ramón Jiménez y el de Kant es que el de este último es meramente conceptual, al menos en el pasaje que hemos citado. No sucede igual en la ingente cantidad de ejemplos mediante los que Kant trata de ilustrar sus conceptos tanto en las tres críticas como en otros textos. Por su parte, el texto de Juan Ramón es claramente afectivo, debido a que los diferentes niveles lingüísticos del poema mantienen una relación de solidaridad con vistas a provocar ese afecto melancólico que nos acomete en el momento en que leemos la confesión del narrador poético. Y volvemos sobre la noción de "afepto": que el texto poético de Juan Ramón sea preponderamente afectivo no quiere decir que no encarne un modelo de mundo en el que el tiempo y el espacio de dicho mundo se ven como ajenos al sujeto de la experiencia. El hecho de que esas dos dimensiones, la afectiva y la conceptual, sean inseparables, es lo que nos llevó a decir mediante un neologismo que el plano artístico se caracteriza por adoptar una modalidad afeptiva.

Lo que estamos tratando de decir es que toda propiocepción o percepción del mundo implica un modelo de mundo y, a su vez, un concepto de ese mundo. No es posible distinguir, como hacen Deleuze y Guattari, el afecto-percepto (propio según ellos del arte) del concepto específico de la filosofía. Cuando Juan Ramón escribe:

Y yo me iré. Y se quedarán los pájaros cantando.

Y se quedará mi huerto con su verde árbol, y con su pozo blanco.

Insistamos en estos versos para poner de relieve que el futuro que domina los tiempos del poema (me iré, se quedarán, se quedará) es imposible de separar de la forma en que el poeta percibe esos pájaros que cantan, ese huerto con el verde árbol, y ese pozo blanco, de un concepto de mundo pensado como lo que el ser humano deja en el momento de su muerte, como un mundo independiente del sujeto. Cierto que Juan Ramón podría haber dicho como Kant algo como "si suprimiéramos nuestro sujeto o simplemente el carácter subjetivo de los sentidos en general, todo el carácter de los objetos, todas sus relaciones espaciales y temporales, incluso el espacio y el tiempo mismos, desaparecerían", y decirlo así conceptualmente. Pero su modo de significación cambia. La primera constatación (y yo me iré) es una verdad universal, se irá ese "yo" del mismo modo que se irá cualquier otro yo. Pero la afirmación acerca de lo que se quedará detrás una vez él se vaya forma parte simultáneamente de un concepto de mundo y de un afecto-percepto del mundo. El poema percibe la realidad de su entorno como algo que se quedará tras su muerte.

Dicho en otros términos: la percepción del mundo viene determinada por el modelo de mundo que sostiene la subjetividad y el discurso literario u otro tipo de discurso. El término "afepto" designa 
precisamente ese carácter precedente dado que ubica el modelo de mundo significante como antecedente de cualquier percepto del mundo.

Veamos un ejemplo notable. ¿Es el mar un fenómeno en sí apetecible, válido por igual para los hombres de nuestros días, para los medievales o para la gente que vivió en Egipto? ¿Qué hay de más natural que acercarse en verano a la playa? En ciertos casos, se toma el coche y se va a la playa, en otros se alquila un apartamento, y en otros se tiene una apartamento pequeño, o una casa grande en la playa. Ese frescor del agua, ese olor a agua del mar, ese sonido del ritmo de las olas. Alberti escribía en los años veinte en su libro titulado precisamente Marinero en tierra:

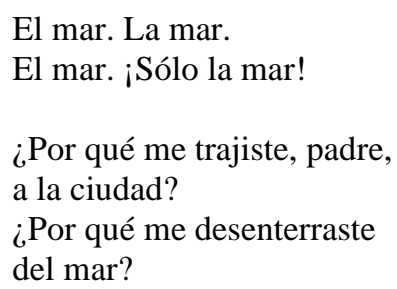

No es únicamente ansiar durante el verano el mar, sino maldecir el haber salido de él, el haber sido arrastrado a la tierra. ¿Pero vemos de verdad el mar? La primera imagen del film de Hitchcock To Catch a Thief se corresponde con el escaparate de una agencia de viajes donde podemos ver unos carteles en los que el protagonista es el paisaje del mar y de la costa francesa (la Costa azul, Niza), convertidos en objeto de deseo. La imagen se mantiene unos minutos mientras van apareciendo los créditos y la cámara se acerca al escaparate un poco más. De repente, un salto en el montaje nos lleva a un primer plano de una mujer mayor con la cara desfigurada, reluciente y brillante por las cremas, gritando que le han robado sus joyas. En menos de dos minutos hemos pasado desde el encanto de unos carteles publicitarios al desencanto que supone el descubrir un robo.

La segunda secuencia funciona como el desmontaje de la primera. Pero no pasa nada, todo el mundo sabe que en la playa, como en otros lugares, se roba, se disgusta la gente, alguien se ahoga, la crema protectora puede experimentarse como pringosa, desagradable, e incluso, a veces, la intensidad de los rayos solares es molesta, quema la piel. Así es la playa y la orilla del mar ${ }^{7}$.

La pregunta es: ¿no estará la percepción del mar y su costa en una relación de dependencia respecto al modelo de mundo que le precede? El libro de Alain Corbier, Le territoire du vide (1988), demuestra precisamente que, en efecto, el mar y sus costas está como efecto y percepto dependiendo de un determinado modelo de mundo. Veamos, ¿a quién en la época clásica se le ocurriría hablar de los encantos de las playas marinas, del placer de afrontar las olas y de la salud que se desprende de una estancia marina? Un modelo de mundo que viene dado por los relatos del Génesis, los Salmos y el Libro de Job, marca la representación del mar y de sus orillas como algo abismal. Como escribe Corbain: "El océano es sólo un recipiente abismal de detritus; lo más positivo que podría decirse de él

\footnotetext{
${ }^{7}$ Este análisis del mundo en tanto modelo de mundo fosilizado fue desarrollado en Asensi (2018). Allí se puede encontrar desarrollado este breve apunte sobre el mar.
} 
es que constituye el menos feo de los paisajes resultantes del retorno temporal del caos" (Corbain, 1993: 16).

Si ahora ponemos los pájaros que cantan, el pozo blanco y el huerto verde en el lugar del mar, entenderemos de inmediato a qué nos referimos cuando decimos que los afectos y los perceptos que aparecen en el poema de Juan Ramón dependen de un modelo de mundo discursivamente configurado. El hecho de que tras su muerte su espíritu vague por los lugares donde vivió el cuerpo, da a entender que ese modelo de mundo está compuesto en su fundamento por una teología cristiana, la cual se trasluce en Juan Ramón por vía consciente o inconsciente.

Está claro que un percepto no es una percepción, pero sea como sea la creación de un percepto en el arte no puede estar sino mediatizada por un determinado concepto de mundo, sin el cual no se podría sostener. El percepto melancólico creado por Juan Ramón, su miedo a la muerte bien conocido, su neurosis de angustia, carecería de base y se volatilizaría si no fuera porque hay un modelo de mundo en el que el tiempo y el espacio sobreviven a las personas. En ese modelo, el espíritu de un hombre o una mujer puede errar, de forma literal o figurada, por un rincón del huerto en el que ese hombre o esa mujer vivieron.

La idea que hemos ido construyendo a lo largo de las páginas anteriores nos llevan a la conclusión de que la filosofía y la literatura, o el arte, forman una amalgama solo diferenciada por su modalidad expresiva, pero que en su núcleo, al estar el modelo de mundo discursivo en el origen de toda textualidad, se indeferencian. Lo conceptual de todo modelo de mundo precede, al igual que el significante lacaniano, a toda expresión concreta. Juan Ramón Jiménez no discute abiertamente con Spinoza, Kant, Heidegger o Sartre entre otros, pero en el modelo de mundo que trasmite en su poesía, así como en el silogismo que lo acompaña, deja ver una posición que puede entrar en conflicto o acompañar a los discursos filosóficos.

\section{Referencias bibliográficas}

Alonso, D. (1966). Poesía española: ensayo de métodos y límites estilísticos: Garcilaso, Fray Luis de León, San Juan de la Cruz, Góngora, Lope de Vega, Quevedo. Madrid: Gredos.

AsEnsi PÉrez, M. (2016). Teoría de los modelos de mundo y teoría de los mundos posibles. Actio Nova: revista de teoría de la literatura y literatura comparada, número 0: 38-55.

ASENSI PÉREZ, M. (2018). ¿Por qué el mundo sí que existe? (Lacan y la teoría de los mdeolos de mundos). En G. Colaizzi, M. de la Fuente, S. Renard y S. Zunzunegui (Eds.), De la escritura como resistencia. Textos in honorem Jenaro Talens (pp. 661-676). Valencia: Universitat de València.

Austin, J. L. (1962). How to do things with words. Oxford: Oxford University Press. Trad. esp. Cómo hacer cosas con palabras. Palabras y acciones. Buenos Aires-Barcelona: Paidós, 1982.

Corbain, A. (1988). Le territoire du vide, Paris, Aubier. Trad. esp de Anielle Lacascade: El territorio del vacío. Barcelona: Mondadori, 1933. 
De Lauretis, T. (1987). Technologies of Gender: Essays on Theory, Film, and Fiction (Theories of Representation and Difference). Bloomington: Indiana University Press.

Deleuze, G. y GuATtari, F. (1993). ¿Qué es la filosofía? Barcelona: Anagrama.

De MAN, P. (1990). Alegorías de la lectura. Lenguaje figurado en Rousseau, Nietzsche, Rilke y Proust. Barcelona: Lumen. Ed. inglesa en Yale University Press, 1979.

DERRIDA, J. (1972). Signature evenement context. En Marges de la philosophie. Paris: Minuit.

DERRIDA, J. (1988). Limited Inc. Evanston: Northwestern University Press.

FANON, F. (2009). Piel negra, máscaras blancas. Madrid: Akal.

Gómez Redondo, F. (ed.) (1996). Juan Ramón Jiménez. Selección poética. Madrid: Alhambra Longman.

KANT, I. (1978). Crítica de la razón pura. Prólogo, traducción, notas e índices de Pedro Ribas. Madrid: Ediciones Alfaguara.

LaCAN, J. (2006). Le Séminaire de Jacques Lacan. Libre XVIII: D’un discours qui ne serait pas du semblant. Paris: Éditions du Seuil.

Mukarovski, J. (2000). Signo, función y valor. Estética y semiótica del arte de Jan Mukarovsky. Edición, introducción y traducción de Jarmila Jandovà y Emil Volek. Colombia: Plaza y Janés Editores.

TRNKA ET ALII (1971). El círculo de Praga. Barcelona: Anagrama. 